GARCH Model with Cross-sectional Volatility; GARCHX Models

Soosung Hwang and Steve Satchell 


\title{
GARCH Model with Cross-sectional Volatility; GARCHX Models
}

\author{
Soosung Hwang ${ }^{1}$ \\ Faculty of Finance \\ City University Business School \\ Steve E. Satchell \\ Faculty of Economics and Politics and Trinity College \\ Cambridge University \\ December 2001
}

\footnotetext{
${ }^{1}$ Faculty of Finance, City Univeristy Business School, Frobisher Crescent, Barbican Centre, London EC 8HY, UK. Tel) +44 (0)20 7477 0109, Fax) +44 (0)20 74778881 , Email) s.hwang@city.ac.uk. I would like to thank M. Salmon for their helpful comments.
} 


\begin{abstract}
This study introduces GARCH models with cross-sectional market volatility, which we call GARCHX model. The cross-sectional market volatility is equlvalent to common heteroskedasticity in asset specific returns, which was suggested by Connor and Linton (2001) as an important component in individual asset volatility. Using UK and US data, we find that daily return volatility can be better specified with GARCHX models, but GARCHX models do not necessarily perform better than conventional GARCH models in forecasting.
\end{abstract}

Keyword Cross-sectional Volatility, GARCHX, Forecasting Volatility

JEL Code C21, C22 


\section{Introduction}

Volatility has long been used as a risk measure. Traditionally, volatility represented by variance (or standard deviation) is decomposed into diversifiable and non-diversifiable components. This measure of volatility, however, is unconditional and does not recognize that there are interesting patterns in asset volatility; e.g., time-varying and clustering properties. Over the last two decades financial econometricians have introduced various models to explain and predict these patterns in volatility. One of the important volatility models is the autoregressive conditional heteroskedasticity (ARCH) family of models introduced by Engle (1982). Another important model is the stochastic volatility (SV) model introduced by Taylor (1986) and Hull and White (1987) among others.

In this study, we introduce a GARCH model that includes market volatility as an additional explanatory variable. The motivation of using the market volatility is to include cross-sectional relationship between asset returns and market returns in linear factor models. With the proposed model, we are able to investigate if there is a market wide common component in volatility and find if the common component is useful for explaining and forecasting individual stock volatility.

Since Fama and French (1993) introduced some accounting factors in linear regression framework, linear factor models have been increasingly popular. When we accept linear factor models as our return process, volatility of a stock is crosssectionally decomposed into multiple components of the factors. A recent study on this area by Campbell, Lettau, Malkiel, and Xu (2001) decomposed the total volatility of a stock into three components, market volatility, industry volatility, and firm specific (idiosyncratic) volatility, and then showed that the market volatility is an important component of the stock volatility and tends to lead the idiosyncratic volatility. 
One major problem in including market volatility into the GARCH framework is the appropriate choice of market volatility. The squared values of market returns or factor values are highly noisy and may not work in conditional volatility models; see Andersen and Bollerslev (1997) and Hwang (2001b) for example. An increasingly popular method to obtain less noisy and parameter free volatility is to use high frequency data; for example, daily volatility can be obtained by measuring summations of intra-day squared returns. For studies using this method, see Andersen and Bollerslev (1997), Andersen, Bollerslev, Diebold, and Labys (1999) and Campbell, Lettau, Malkiel, and Xu (2001) among others.

In this study we use cross-sectional market volatility. The cross-sectional market volatility is a measure of disperse of individual asset returns with respect to the market return for a given time. Hwang (2001a), using linear factor models, showed that there is an analytical relationship between cross-sectional market volatility and timeseries market volatility. He compared the properties of the cross-sectional market volatility with those of time-series market volatility such as squared market returns and conditional market volatility in the UK and US markets. The empirical results showed that cross-sectional market volatility is not only highly correlated with time-series market volatility but also more informative than squared market returns, suggesting that cross-sectional market volatility can be useful for the explanation and forecasting of time-series market volatility.

The cross-sectional market volatility can be considered common volatility in market. Recently, Connor and Linton (2001), using a large number of monthly UK equity returns, showed that the dynamic heteroskedasticity can be decomposed into three components; common factor-related heteroskedasticity, common heteroskedasticity in asset-specific returns, and purely asset specific heteroskedasticity. They found evidence of common heteroskedasticity in asset-specific returns. The cross-sectional market volatility in our study is equivalent to the common heteroskedasticity in 
asset-specific returns which is a cross-sectional average of individual volatility. In addition, since the cross-sectional and time-series market volatility is related both analytically and empirically (Hwang, 2001a), the common factor-related (market factor related) heteroskedasticity may also be explained with the cross-sectional market volatility.

We call our model GARCHX models since the constant in GARCH models is replaced by an extra term, i.e., the lagged cross-sectional market volatility, and thus the GARCHX model does not need additional parameters. Note that the cross-sectional market volatility is lagged to make the GARCHX mode conditional. The GARCHX model is simple, but includes information on some important factors, especially the market factor, via the cross-sectional volatility. Our model is a special case of the multivariate Factor-GARCH model of Engle, Ng, and Rothchild (1990) in the sense that only one factor, i.e., the market factor is included. Note that the main problem in the multivariate GARCH models is that the number of parameters to be estimated grows very fast and we need to impose some restrictions to make the conditional covariance matrix positive definite. Several methods have been suggested to solve these problems; see chapter 12, Campbell, Lo, and MacKinlay (1997).

GARCHX models are also a generalised version of models by Braun, Nelson, and Sunier (1995) and Glosten, Jagannathan, and Runkle (1993), but different from Braun, Nelson, and Sunier (1995) in the sense that cross-sectional volatility is used. A different version of GARCHX models was introduced by Apergis (1998) to investigate how short-run deviations from the relationship between stock prices and certain macroeconomic fundamentals affect stock market volatility. In the Apergis model, the squared past error-correction term which represents the short run deviations is added to the GARCH conditional volatility. GARCHX models may be considered a simplified version of Connor and Linton (2001). Without using complicated econometric models, we examine if the inclusion of the common heteroskedasticity 
in factors and asset specific returns can improve modelling volatility and also if it can be used for forecasting volatilities.

Using 10 years UK and US daily data, we show that the return volatility (i.e., squared returns) of an individual stock can be better specified with GARCHX models than with GARCH models. The maximum likelihood values, significance of the parameter on the cross-sectional market volatility, and some other statistics show that GARCHX models perform better than GARCH models in general. We also use GARCHX models for forecasting return volatility. As expected, GARCHX models show little improvement in forecasting performance for return volatility which is highly noisy in the GARCH framework. See Andersen and Bollerslev (1997) for the detailed explanation on the difficulties of forecasting return volatility with GARCH models.

This study shows that common cross-sectional heteroskedasticity in stock returns is an important component in conditional volatility models. We find evidence that more than three-quarters of individual stocks included in the FTSE350 and S\&P500 show a significant coefficient on the lagged cross-sectional market volatility. If we allowed current cross-sectional market volatility, we may get stronger evidence of common volatility for the explanation of individual stock volatility. This finding is consistent with Jones (2001) and Connor and Linton (2001) who suggested common volatility as an important source of individual stock volatility. We also show how much of an individual stock volatility can be explained by common volatility. We find that on average $12 \%$ to $16 \%$ of individual volatility is explained with the market common volatility. This is what Campbell, Lettau, Malkiel, and Xu (2001) found during a similar sample period with monthly data.

Cross-sectional volatility can also be used in stochastic volatility (SV) models; SVX models. We expect such models work as well as in the GARCHX context. In this study we consider the market factor only. However, other factors may also be 
included. We leave these for future research.

In the next section, we explain why cross-sectional market volatility may be included for conditional volatility models and introduce GARCHX models. In section 3, using UK and US data, we show that squared return can be better specified with GARCHX models than with GARCH models and how GARCHX models can be used for volatility forecasting. Conclusions are in section 4 .

\section{GARCH Models with Cross-sectional market Volatility}

The introduction of GARCHX models needs explanation of cross-sectional expectation for cross-sectional statistics such as mean and variance.

\subsection{Time-series and Cross-sectional Expectation}

In this section, we define a notion of expections essentially equivalent to weighted moments. For any variable $x_{i t}$, where $i=1,2, \ldots, N$ and $t=1,2, \ldots, T$, the timeseries expectation is defined as

$$
E^{T}\left(x_{i t}\right)=\frac{1}{T} \sum_{t=1}^{T} x_{i t} \text { for } i=1,2, \ldots, N .
$$

On the other hand, the cross-sectional expectation for the variable $x_{i t}$ is defined to be

$$
E^{C}\left(x_{i t}\right)=\sum_{i=1}^{N} w_{i t} x_{i t}, \text { for } t=1,2, \ldots, T,
$$

where $w_{i t}$ is an appropriate cross-sectional weight on asset $i$ at time $t$. This weight may be a probability measure if $w_{i t} \geq 0$ for all $i$ and $t$, and $\sum_{i=1}^{N} w_{i t}=1$ for all

$t$. One simple example is $w_{i t}=\frac{1}{N}$ for all $i$ so that $E^{C}\left(x_{i t}\right)=\frac{1}{N} \sum_{i=1}^{N} x_{i t}$ which is an equally weighted cross-sectional average at time $t$, corresponding to a discrete version of the uniform distribution. 
Cross-sectional expectations can therefore be thought of as taking expectations with respect to a measure where the weights are determined by the market. Note that we have the time-series expectation for each asset so that we have $N$ expectations, whilst we have $T$ cross-sectional expectations. Using the definition of expectations above, we can calculate the mean, variance, skewness, and kurtosis in both the time-series and cross-sectional world.

A simple, but widely used method to obtain time-series volatility is to apply a return process to calculate errors and then square them. For example, the $\operatorname{AR}(1)$ process may be used as the return process to calculate errors. That is, for returns, $r_{i t}$,

$$
r_{i t}=a_{i}+b_{i} r_{i t-1}+\varepsilon_{i t}
$$

where $a$ and $b$ are parameters, volatility is calculated by estimating $\varepsilon_{i t}^{2}$. Skewness and kurtosis can also be obtained by estimating $\varepsilon_{i t}^{3}$ and $\varepsilon_{i t}^{4}$, respectively.

On the other hand, cross-sectional market volatility needs many asset returns in the market. Suppose that there are $N$ assets in the market. Then, the cross-sectional market return at time $t$ is

$$
r_{m t}=\sum_{i=1}^{N} w_{i t} r_{i t}
$$

which is equivalent to the (equally or value weighted) market return at time $t$. Thus, one definition of cross-sectional market volatility, $\sigma_{C, m t}^{2}$, is

$$
\sigma_{C, m t}^{2}=\sum_{i=1}^{N} w_{i t}\left(r_{i t}-r_{m t}\right)^{2} .
$$

Therefore, the cross-sectional volatility represents volatility calculated across a universe of stocks. When residuals obtained with a linear factor model are used, the calculated cross-sectional market volatility is equivalent to the common asset specific volatility of Connor and Linton (2001).

Cross-sectional skewness and kurtosis can also be calculated accordingly. These statistics can be calculated for an industry level, or a specific set of stocks such as 
a portfolio. In the special case that $w_{i t}=\frac{1}{N}$, equation (4) gives the practitioners notion of cross-sectional volatility of a portfolio. Therefore, an individual asset's cross-sectional volatility does not exist.

\subsection{GARCHX Models}

The model we propose uses the lagged cross-sectional market volatility as an additional explanatory variable in the conventional GARCH model. This is a special case of the factor-ARCH model by Engle, Ng, and Rothchild (1990). However, Hwang (2001a) argues that the cross-sectional volatility provides more information on the time-varying factors than the time-series volatility. Thus, we propose a simple conditional volatility model including the cross-sectional market volatility. Our model avoids the econometric hurdle of ensuring the positivity of conditional volatility in the factor-ARCH model, while providing better results than the conventional GARCH model.

Let us first consider the following cross-sectional relationship between the returns of asset $i$ and the returns of the market portfolio and $K$ factors;

$$
r_{i t}=\beta_{0 i}+\beta_{m i} r_{m t}+\beta_{1 i} f_{1 t}+, \ldots,+\beta_{K i} f_{K t}+\zeta_{i t}
$$

where $\beta_{0 i}, \beta_{m i}$ and $\beta_{k i}, k=1, \ldots, K$, are parameters, and $\zeta_{i t}$ is a mean zero error process, $\zeta_{i t} \sim N\left(0, \sigma_{i \zeta}^{2}\right)$, and $r_{m t}$ and $f_{k t}$ are the market portfolio return and the realised value of factor $k$ at time $t$. As in conventional linear factor models, we assume that the explanatory variables, $r_{m t}$ and $f_{k t}$ are orthogonal, and $r_{i t}$ and $r_{m t}$ represent excess returns calculated with risk free returns. Factors may be macroeconomic, firm specific characteristics, or based on market micro-structure, see Chen, Roll, and Ross (1986), Schwert (1989), Fama and French (1992), Lakonishok, Shleifer and Vishny (1994), Basu (1977) for example.

The model in (5) implies that there are multiple factors; the market portfolio 
and $K$ other factors. Therefore, the model is a multi-factor-GARCH model. The expected return conditional on $t_{t-1}$ available up to time $t-1$ is

$E_{t-1}^{T}\left[r_{i t} \mid{ }_{t-1}\right]=\beta_{0 i}+\beta_{m i} E_{t-1}^{T}\left[r_{m t} \mid{ }_{t-1}\right]+\beta_{1 i} E_{t-1}^{T}\left[f_{1 t} \mid{ }_{t-1}\right]+, \ldots,+\beta_{K i} E_{t-1}^{T}\left[f_{K t} \mid{ }_{t-1}\right]$.

Using (5) and (6), we have the volatility of the return on asset $i$ at time $t^{1}$

$$
\epsilon_{i t}^{2}=\beta_{m i}^{2} \epsilon_{m t}^{2}+\beta_{1 i}^{2} \epsilon_{1 t}^{2}+, \ldots,+\beta_{K i}^{2} \epsilon_{K t}^{2}+\zeta_{i t}^{2}
$$

where $\epsilon_{i t}=r_{i t}-E_{t-1}^{T}\left[r_{i t} \mid{ }_{t-1}\right], \epsilon_{m t}=r_{m t}-E_{t-1}^{T}\left[r_{m t} \mid{ }_{t-1}\right]$ and $\epsilon_{k t}=f_{k t}-E_{t-1}^{T}\left[f_{k t} \mid{ }_{t-1}\right]$. The above equation shows the cross-sectional relationship between individual asset's time-series volatility and factor volatilities.

Note that there is a significant difference between $\beta_{m i}$ and $\beta_{k i}$. The cross-sectional average of $\beta_{m i}$ is one, whilst those of $\beta_{k i}$ are zero; see Hwang and Salmon (2001) for further discussion. This means that $\beta_{m i}$ is distributed around one, whilst $\beta_{k i}$ is distributed around zero. In addition, in many cases, the coefficients on factors other than the market factor are not significantly different from zero; see Hall, Hwang, and Satchell (2001) for example. Campbell, Lettau, Malkiel, and Xu (2001) also showed that market volatility and firm asset specific volatility are the important components for the explanation of individual asset volatility. ${ }^{2}$ Furthermore, when we take squared values of $\beta_{m i}$ and $\beta_{k i}, \beta_{m i}^{2}$ may still be significant in many cases but $\beta_{k i}^{2}$ may not. In addition, the identification of factors other than the market factor is generally difficult and controversial. Thus as long as our universe is one rational market, we may approximate asset $i$ 's return volatility with the following

\footnotetext{
${ }^{1}$ Generally if factors are not orthogonal to each other, then there should be cross-product terms in the equation, resulting in multi-factor volatility models as in Engle, Ng, and Rothchild (1990).

${ }^{2}$ We do not use industry volatility in our study. However, the industry volatility is also an important component in the individual asset volatility as shown in Campbell, Lettau, Malkiel, and $\mathrm{Xu}$ (2001), and can be included in our model.
} 
cross-sectional relationship with market volatility;

$$
\epsilon_{i t}^{2} \approx \beta_{m i}^{2} \epsilon_{m t}^{2}+\zeta_{i t}^{2}
$$

The popular GARCH $(1,1)$ process for asset $i$ is

$$
h_{i t}=\alpha_{i 0}+\alpha_{i 1} \epsilon_{i t-1}^{2}+\alpha_{i 2} h_{i t-1},
$$

where $h_{i t}$ is the conditional volatility of asset $i$ at time $t$. GARCH models uses past volatility and conditional volatility to explain the current conditional volatility. However, in GARCH models we do not find market volatility which may be an important component in volatility. That is, the important cross-sectional relationship between the market volatility and the individual asset's volatility in (7) is not included in the conventional GARCH model.

One way to include market volatility in the GARCH $(1,1)$ model is

$$
h_{i t}=\alpha_{i 0}+\alpha_{i 1} \epsilon_{i t-1}^{2}+\alpha_{i 2} h_{i t-1}+\alpha_{i 3} \epsilon_{m t-1}^{2} .
$$

This is the same as the GARCH-X model proposed by Apergis (1998). Throughout this study, we call the model in (9) GARCHX-T(1,1) model to differentiate from our GARCHX models. For the GARCHX-T $(1,1)$ model to be stationary, we need

$$
\alpha_{i 1}+\alpha_{i 2}<1
$$

as in the ordinary GARCH $(1,1)$ model. However, one major problem in the above model is the non-negativity condition. For the conditional volatility process in (9) to be always positive, we need

$$
\alpha_{i 0}>0, \alpha_{i j} \geq 0, j=1,2,3
$$

However, during empirical estimation, we face many cases which have $\alpha_{i 0} \leq 0$ but still

$$
\frac{1}{T} \sum_{t=2}^{T}\left(\alpha_{i 0}+\alpha_{i 3} \epsilon_{m t-1}^{2}\right)>0
$$


The condition in (12) is not necessary and sufficient for the positiveness of the conditional volatility $h_{i t}$ in (9), but the conditions in (11) seem to be too strong in empirical calculation. We tried to estimate model (9) using conditions (11) and (12) and found many cases where the strict nonnegativity condition of (11) is too strong. In addition, one more parameter needs to be estimated than the $\operatorname{GARCH}(1,1)$ model. ${ }^{3}$

An alternative model is

$$
h_{i t}=\alpha_{i 0} \epsilon_{m t-1}^{2}+\alpha_{i 1} \epsilon_{i t-1}^{2}+\alpha_{i 2} h_{i t-1} .
$$

Here, for stationarity and nonnegativity

$$
\alpha_{i 1}+\alpha_{i 2}<1, \alpha_{i 0}>0, \alpha_{i 1} \geq 0, \alpha_{i 2} \geq 0
$$

which is exactly the same as the ordinary GARCH model. The unconditional variance of asset $i$ is

$$
E^{T}\left[h_{i t}\right]=\frac{\alpha_{i 0} E^{T}\left[\epsilon_{m t-1}^{2}\right]}{1-\alpha_{i 1}-\alpha_{i 2}} .
$$

One problem of the above (9) and (13) models is that $\epsilon_{m t}^{2}$ is highly noisy over time in the GARCH frame work; see Andersen and Bollerslev (1998) for example. Therefore allowing one lag for $\epsilon_{m t}^{2}$ and thus using $\epsilon_{m t-1}^{2}$ instead of $\epsilon_{m t}^{2}$ may not improve the model.

The empirical test results in Hwang (2001a) suggest that the cross-sectional market volatility, $\sigma_{C, m t}^{2}$, is more informative than the time-series market volatility, $\epsilon_{m t}^{2}$, and highly persistent. Connor and Linton (2001) and Jones (2001) suggested that there is common heteroskedasticity in asset specific returns, which may be replicated

\footnotetext{
${ }^{3}$ To aviod the nonnegativity constraints, we may use logarithmic function as in exponential GARCH; see Braun, Nelson, and Sunier (1995) for example. We applied the logarithmic function to the volatility process to make the voalitlity process such as log-ARFIMA model (Hwang and Satchell, 1998), but the model does not seem to work well. In this study we confine our studies on cross-sectional volatility to GARCH models. The EGARCH-cross-sectional volatility process is not too difficult to set up and left for future studies.
} 
by the cross-sectional market volatility. Therefore, we propose the GARCH-crosssectional (GARCHX) model;

$$
h_{i t}=\alpha_{i 0} \sigma_{C, m t-1}^{2}+\alpha_{i 1} \epsilon_{i t-1}^{2}+\alpha_{i 2} h_{i t-1}
$$

where, using $E^{C}[$.$] as defined in (1),$

$$
\begin{aligned}
\sigma_{C, m t-1}^{2} & =E^{C}\left[\left(r_{i t-1}-r_{m t-1}\right)^{2}\right] \\
r_{m t-1} & =E^{C}\left[r_{i t-1}\right]
\end{aligned}
$$

and the stationarity and nonnegativity conditions are in (14). Note that we allow one lag for the cross-sectional market volatility as $\sigma_{C, m t-1}^{2}$ in equation (15). We expect the GARCHX model performs better than the GARCHX-T model because $\sigma_{C, m t}^{2}$ is more informative and highly persistent.

Equation (15) is the $\operatorname{GARCHX}(1,1)$ model and we generalise this to the $\operatorname{GARCHX}(p, q)$ model;

$$
h_{i t}=\alpha_{i 0} \sigma_{C, m t-1}^{2}+\sum_{q=1}^{Q} \alpha_{i q} \epsilon_{i t-q}^{2}+\sum_{p=1}^{P} \gamma_{i p} h_{i t-p}
$$

and for stationarity and nonnegativity, we need

$$
\begin{aligned}
\sum_{q=1}^{Q} \alpha_{i q}+\sum_{p=1}^{P} \gamma_{i p} & <1 \\
\alpha_{i 0} & >0 \\
\alpha_{i q} & \geq 0, q=1, \ldots, Q \\
\gamma_{i p} & \geq 0, p=1, \ldots, P .
\end{aligned}
$$

In terms of comparing our analysis with Campbell, Lettau, Malkiel, and Xu (2001) who cross-sectionally decomposed volatility into market/sector/idiosyncratic level, we do not include industry factors and so a direct comparison is difficult. Our model uses a cross-sectional market volatility as a component of a time series. 


\section{Empirical Tests}

We estimate $\operatorname{GARCH}(1,1)$ in $(8), \operatorname{GARCH}(1,1)$ with the time-series market volatility (13) denoted by GARCHX-T, and GARCHX $(1,1)$ with the cross-sectional volatility (15) denoted by GARCHX for all individual stocks included in the FTSE350 and S\&P500.

\subsection{Data}

We use the same data as in Hwang (2001a), which consist of individual asset returns included in the FTSE350 and the S\&P500. Daily log-returns are calculated from 11 December 1989 to 9 December 1999. The data consist of 350 assets for the UK market, each of which consists of maximum 2533 log-returns during the sample period and 500 assets for the USA market, each of which has maximum 2527 logreturns during the sample period. We obtained the data from Datastream.

Note that since the components of the indices have changed during the sample period, we used equities included in the indices as of the 10th of December, 1999. Thus, the number of equities available at the beginning of our sample period is less than the number of equities in the indices at the end of our sample period. Our results may be affected by this exclusion of equities in the early period of our sample. However, the effects are not expected to be significant because of the large number of equities used here (350 in the UK market and 500 in the USA market). In addition, changes in the components of the indices are usually for small companies. The numbers of equities at the beginning of our sample period are 242 and 430 for the FTSE350 and S\&P500 indices. For these equities, we have the full 10 years' daily log-returns, while for other equities, we have shorter observations.

We do not use log-returns which are larger than $50 \%$ or smaller than $-50 \%$ a day. In this study we define these returns outliers. The total number of equities 
removed were 17 in the FTSE350 constituents and 9 in the S\&P500 constituents. For the calculation of equally weighted cross-sectional market returns and volatility, $w_{i t}$ is set to $\frac{1}{N}$ as in (3) and (4), whilst for the value weighted cross-sectional market returns and volatility, $w_{i t}$ is set to the market weights on individual assets. For the calculation of time-series volatility, we use (2) for both equally weighted market returns and value weighted market returns.

\subsection{Specification Tests of GARCHX Model}

Table 1 summaries some statistical properties of the cross-sectional and time-series market volatilities. ${ }^{4}$ We find that cross-sectional returns are more dispersed than time-series returns; the average standard deviation of cross-sectional returns is larger than that of time-series returns. The time-series volatility of the value weighted return is larger than that of the equally weighted return, while the cross-sectional volatility of the value weighted return is smaller than that of the equally weighted return. This is the result of heavy weights on some large equities. Another interesting property in volatility is that the cross-sectional volatility is highly persistent, whilst the time-series volatility shows far less persistence. The high persistence of the cross-sectional volatility empirically suggests that GARCHX models perform better than GARCHX-T models. Table 1 also shows the relationship between crosssectional and time-series volatility. The correlations between them are around 0.4 and there is little difference between the four cases. This gives a reason why we put cross-sectional volatility in the conditional volatility models such as GARCH.

We use cross-sectional market volatility in GARCH models as suggested in the previous section. For the GARCHX and the GARCHX-T models, both equallyweighted and value-weighted volatilities are used. Thus, altogether we have five

\footnotetext{
${ }^{4}$ The source of table 1 is table 1 of Hwang (2001). More detailed empirical results on the cross-sectional statistics can be found in Hwang (2001).
} 
models; GARCH(1,1), GARCHX $(1,1)$ with equally weighted cross-sectional market volatility $(\operatorname{GARCHX}(\mathrm{EW}))$, GARCHX $(1,1)$ with value weighted cross-sectional market volatility (GARCHX(VW)), GARCHX-T(1,1) with equally weighted time-series market volatility (GARCHX-T(EW)), and GARCHX-T(1,1) with value weighted time-series market volatility (GARCHX-T(VW)).

Table 2 summarises the estimation results. The first results reveal how easily we can estimate the models. The number of converged cases provides some information about this question. For the conventional $\operatorname{GARCH}(1,1)$ model, we have 323 convergences out of 333 for the FTSE350 equities and 483 convergences out of 491 S\&P500 equities, respectively. The numbers of converged cases for the GARCHX is nearly the same as those for the $\mathrm{GARCH}(1,1)$ model. In addition, the estimation time does not seem to be increased dramatically with cross-sectional volatility. However, the GARCHX-T seems to suffer convergence problems. Most of the convergence errors occur because of the non-negativity condition on the coefficient of the past market volatility, i.e., $\alpha_{i 0}>0$ in (13).

A more direct comparison between the five models is possible using the maximum likelihood (ML) values. In table 2 we reported the number of cases that the ML values of GARCHX and GARCHX-T models are larger than those of the GARCH model. Note that the comparisons are possible only when we have converged estimates. Furthermore there is no need to adjust for "the number of parameters" as both models have the same number of parameters.

First, the GARCHX model performs very well; for example, the cases that the GARCH model performs better than the other four models are 46 (16.5\%) and $33(7.8 \%)$ for the FTSE and S\&P500 equities, respectively. Other statistics such as portmanteau tests also suggest that GARCHX models perform well. The numbers of significant serial correlations in the squared standardised error in the $\operatorname{GARCH}(1,1)$ model for 5, 10, 20 lags are decreased in GARCHX models. For example, the 
percent of significant correlations at $95 \%$ level with the first five lags $(\mathrm{Q}(5))$ in the GARCH $(1,1)$ model are $9.60 \%$ and $17.39 \%$ for the FTSE350 and S\&P500, while those statistics are $6.11 \%$ and $8.92 \%$ in $\operatorname{GARCHX}(\mathrm{EW}) .{ }^{5}$ On the other hand, the statistics of skewness and kurtosis of the standardised residuals are not improved.

The GARCHX-T models perform poorly compared with GARCH or GARCHX models. The number of the ML values larger than those of GARCH are around 25$42 \%$ of the total number of equities. The poor performance of GARCHX-T model is not surprising when we consider the relatively large amount of noise included in the time-series volatility; see signal-to-noise ratios in table 2, Hwang (2001a).

We next compare GARCH and GARCHX models in detail in table 3. The first comparison is the number of significant $\alpha_{i 0}$ of $\operatorname{GARCH}(1,1)$ in $(8)$ and $\operatorname{GARCHX}$ in (15). The significance increases with cross-sectional volatility; in particular, for the S\&P500, the percentage increases from $56.31 \%$ to more than $70 \%$. This means that the lagged cross-sectional volatility is an important explanatory variable in the presence of the past volatility and past conditional volatility. This result is consistent with Connor and Linton (2001) and Jones (2001). In order to investigate further if the relationship in (7) is still important after one period lag and the replacement of $\epsilon_{m t}^{2}$ (market volatility) with $\sigma_{C, m t-1}^{2}$ (cross-sectional volatility), we also calculate the correlation coefficient between squared betas and coefficients on the past cross-sectional volatility $\left(\alpha_{i 0}\right.$ in the $\operatorname{GARCHX}(1,1)$ model). The betas are estimated using a one factor (market) model. The second rows in panels A and B in Table 3 show that there is still significant positive correlation $(0.16)$ between $\beta_{m i}^{2}$ and $\alpha_{i 0}$ except for the GARCHX(VW) model of the FTSE350 which is negative but not significant. Other correlation coefficients are all positive and significant. This means that the market volatility is an important factor for forecasting individual asset volatility. The results are consistent with Campbell, Lettau, Malkiel, and Xu

\footnotetext{
${ }^{5}$ Note that these statistics should be around $5 \%$ since we use $95 \%$ significance level.
} 
(2001) who found evidence that market volatility Granger-causes individual stock volatility.

We also calculate the proportion of $\alpha_{i 0} \sigma_{C, m t-1}^{2}$ in conditional volatility, which can be interpreted as the proportion of the cross-sectional market volatility in individual stock volatility. The results in Table 3 show that these proportions range between $12 \%$ and $16 \%$, which is consistent with Campbell, Lettau, Malkiel, and Xu (2001), who found that the market volatility accounts for about $13 \%$ for the unconditional mean of individual stock volatility for the period from January 1988 to December 1997. Our study shows that, despite differences in the definition of the market volatilities and in other detail procedures, the overall conclusion is the same; market volatility does matter for the individual stock volatility.

The next rows report results on the ML values. GARCHX(EW) has larger ML values than the GARCH model for 237 and 417 cases, for the S\&P500 and the FTSE350, respectively, which are equivalent to $76.7 \%$ and $86.9 \%$ of the total cases. The average values of the changes in the ML values are all positive. Since there is no change in the number of parameters between the GARCH in (8) and the GARCHX in (15), the positive increase in ML values suggest that GARCHX model performs better than GARCH model. In addition, the average values of portmanteau statistics are decreased slightly in GARCHX models. However, the estimates of skewness show little difference, whilst those of kurtosis tend to increase for GARCHX model.

\subsection{Forecasting Tests of GARCHX Model}

The empirical results in the previous subsection show that return volatility (squared returns) is better specified with GARCHX models. In this subsection, we investigate the forecasting performance of the GARCHX model.

For our data, we use four daily return volatility series of three stocks, i.e., Abbey National, Unilever, British Airways, and one index, i.e., the FTSE100 index. The 
return volatility (RV) is obtained by squaring de-meaned daily log-returns. The total number of 2496 daily returns from 21 January 1992 to 27 November 2001 is used to test the forecasting performance of the GARCHX model. The return series of the underlying asset is provided by Datastream.

In Table $4 \operatorname{GARCH}(1,1)$ and $\operatorname{GARCHX}(1,1)$ estimates of the four return series are reported. The maximum likelihood values of the GARCH model are all larger than those of the GARCHX model for the four cases. Except for British Airways, the estimated coefficients on the past cross-sectional market volatility are significant at the $10 \%$ level. These are some examples of GARCHX estimates as well as other evidence that the common heteroskedasticity in asset specific returns is an important component for individual asset's volatility process.

Another important result in Table 4 is that the inclusion of the cross-sectional market volatility tends to decrease $\alpha_{i 2}$ so that the level of persistence in the $\operatorname{GARCHX}(1,1)$ model, i.e., $\alpha_{i 1}+\alpha_{i 2}$, is less than that in the $\operatorname{GARCH}(1,1)$ model. This indirectly shows that the high persistence frequently found in volatility process may be due to missing time-varying components.

We use a rolling sample of the past volatilities. On day $t$, the conditional volatility of one period ahead, $t+1$, is constructed by using the estimates which are obtained from only the past observations (i.e., 2197 observations in this study). By recursive substitution of the conditional volatility, forecasts for up to 60 horizons are constructed. On the next day $(t+1)$, using 2197 recent observations (i.e., 2197 observations from the second observation to the 2198th observation), we estimate the parameters again and get another forecast for up to 60 horizons. The estimation and forecasting procedures are performed 240 times using rolling windows of 2197 observations. And then, each forecast is compared with the realised return volatility.

For the $\operatorname{GARCH}(1,1)$ model in $(8)$, the one step ahead forecast, $h_{t+1 \mid t}$, and the 
$f$ step ahead forecasts, $h_{t+f \mid t}$, are

$$
\begin{aligned}
h_{i, t+1 \mid t} & =\alpha_{i 0}+\alpha_{i 1} \epsilon_{i t}^{2}+\alpha_{i 2} h_{i t}^{2}, \\
h_{i, t+f \mid t} & =\alpha_{i 0} \sum_{j=0}^{f-1}\left(\alpha_{i 1}+\alpha_{i 2}\right)^{j}+\left(\alpha_{i 1}+\alpha_{i 2}\right)^{f-1}\left(\alpha_{i 1} \epsilon_{i t}^{2}+\alpha_{i 2} h_{i t}^{2}\right), \text { when } f>1,
\end{aligned}
$$

where $h_{i, t+f \mid t}$ represents $f$ step ahead volatility conditional on the information available at time $t$. For large $f, h_{i, t+f \mid t}$ approaches $\frac{\alpha_{i 0}}{1-\alpha_{i 1}-\alpha_{i 2}}$, the unconditional variance for the case $0<\alpha_{i 1}+\alpha_{i 2}<1$. On the other hand, the one step ahead forecast, $h_{i, t+1 \mid t}^{X}$, and the $f$ step ahead forecasts, $h_{i, t+f \mid t}^{X}$, of the $\operatorname{GARCHX}(1,1)$ model are

$$
\begin{aligned}
h_{i, t+1 \mid t}^{X} & =\alpha_{i 0} \sigma_{C, m t}^{2}+\alpha_{i 1} \epsilon_{i t}^{2}+\alpha_{i 2} h_{i t} \\
h_{i, t+f \mid t}^{X} & =\alpha_{i 0} \sigma_{C, m t}^{2} \sum_{j=0}^{f-1}\left(\alpha_{i 1}+\alpha_{i 2}\right)^{j}+\left(\alpha_{i 1}+\alpha_{i 2}\right)^{f-1}\left(\alpha_{i 1} \epsilon_{i t}^{2}+\alpha_{i 2} h_{i, t}^{2}\right), \text { when } f>1,
\end{aligned}
$$

and for large $f, h_{i, t+f \mid t}^{X}$ approaches $\frac{\alpha_{i 0} \sigma_{C, m t}^{2}}{1-\alpha_{i 1}-\alpha_{i 2}}$, the unconditional variance for the case $0<\alpha_{i 1}+\alpha_{i 2}<1$. Equations (17) and (18) clearly show that the forecasting performance depends on the property of $\sigma_{C, m t}^{2}$. However, since the two forecasts, $h_{i, t+f \mid t}$ and $h_{i, t+f \mid t}^{X}$, approach the same unconditional volatility as the forecasting horizon increases, the main difference between the two forecasts lies in short forecasting horizon.

Table 5 shows that, as reported in many other studies, the GARCH model performs poorly for the forecasts of volatility. The mean absolute forecast error is close to the average value of the realised return volatility (squared returns) during the forecasted period. The high volatile return volatility seems to be hard to forecast with the conditional volatility model, and the results are consistent with previous studies such as Andersen and Bollerslev (1997). Our GARCHX model shows smaller MAFE and MSFE than the GARCH model for all four cases in short forecast horizons, but the difference is marginal.

Over the longer horizons, we may not find if the GARCHX model performs better than the GARCH model. As explained above, as the forecasting horizon increases, 
the two forecasts obtained with the GARCH and GARCHX models are similar, the main difference between the two models can be found in the shorter forecasting horizons.

\section{Conclusions}

This study introduces a simple new conditional volatility model called GARCHX using the cross-sectional market volatility. The model is simple, but can be used to explain the proportion of market volatility included in individual stock volatility. The model can also be used to explain common heteroskedasticity in asset returns which was suggested by Jones (2001) and Connor and Linton (2001) as a significant component.

Using the UK and US markets, we find that more than three-quarter cases, the maximum likelihood values of the GARCHX $(1,1)$ model are larger than those of the GARCHX $(1,1)$ model and the coefficients on the cross-sectional market volatility are significant. Therefore, individual stock volatility seems to be better specified with the inclusion of an additional cross-sectional market volatility. However, GARCHX models still are not good enough for forecasting RV.

A few important findings of our study can be summarised as follows. We find that the proportion of the market volatility in an individual stock's conditional volatility ranges from $12 \%$ to $16 \%$ which is consistent with the results of Campbell, Lettau, Malkiel, and Xu (2001). In addition, the large number of the significant coefficients on the cross-sectional market volatility support what Connor and Linton (2001) found. Our study, using a simple model with daily instead of monthly returns for both the UK and US markets, confirms these recent studies.

In this study we include one cross-sectional volatility calculated for market level, but cross-sectional volatility can also be calculated for industry level or for a specific 
portfolio. These cross-sectional volatilities can be incorporated with conditional volatility models such as GARCH models or stochastic volatility models. 


\section{References}

Andersen, T. and T. Bollerslev, 1998, Answering the Skeptics: Yes, Standard Volatility Models Do Provide Accurate Forecasts, forthcoming in International Economic Review.

Andersen, T., T. Bollerslev, F. Diebold, P. Labys, 1999, The Distribution of Exchange Rate Volatility, Working Paper FIN-99-059, Department of Finance, Stern School of Business, New York University.

Bond, S. A., 1999, Time Varying Skewness and Downside Risk Measurement: A Comparison of Models, Unpublished Manuscript, Faculty of Economics and Politics, Cambridge University.

Braun, P A., D. B. Nelson, and A. M. Sunier, 1995, Good News, Bad News, Volatility, and Betas, Journal of Finance 50(5), 1575-1603.

Bulkley, G. and I. Tonks, 1991, Cross-sectional Volatility on the U.K. Stock Market, Manchester School of Economics and Social Studies 59(0), Supplement, 72-80.

Campbell, J., M. Lettau, B. Malkiel, and Y. Xu, 2001, Have Individual Stocks Become More Volatile? An Empirical Exploration of Idiosyncratic Risk, Journal of Finance 56(1), 1-43.

Connor, G. and O.. Linton, 2001, The Common and Specific Components of Dynamic Volatility, Mimeo, London School of Economics and Political Science.

Engle, R. F., 1982, Autoregressive Conditional Heteroskedasticity with Estimates of the Variance of the United Kingdom Inflation, Econometrica 50(4), 987-1007.

Engle, R. F., V. K. Ng, and M. Rothchild, 1990, Asset Pricing with a FACTORARCH Covariance Structure: Empirical Estimates for Treasury Bills, Journal of Econometrics 45, 213-237.

Ferson, W. E. and C. R. Harvey, 1991, The Variation of Economic Risk Premiums, Journal of Political Economy 99(2), 385-415.

Ferson, W. E. and C. R. Harvey, 1991, Sources of Predictability in portfolio returns, 
Financial Analysts Journal 47, 49-56.

Glosten, L. R., R. Jagannathan, and D. E. Runkle, 1993, On the Relation between the Expected Value and the Volatility of the Nomial Excess Return on Stocks, Journal of Finance 48(5), 1779-1801.

Hansen, B. E., 1994, Autoregressive Conditional Density Estimation, International Economic Review 35, 705-730.

Harvey, C. R. and A. Siddique, 1999, Autoregressive Conditional Skewness, Journal of Financial and Quantitative Analysis 34(4), 465-488

Harvey, A. C., E. Ruiz and N. Shephard, 1994, Multivariate Stochastic Variance Models, Review of Economic Studies 61, 247-264.

Harvey, A. C. and N. Shephard, 1993, Estimation and Testing of Stochastic Variance Models, Econometrics discussion paper EM/93/268, London School of Economics. Harvey, A. C. and N. Shephard, 1996, Estimation of an Asymmetric Stochastic Volatility Model for Asset Returns, Journal of Business and Economic Statistics 14, 4, 429-34.

Hull, J. C., and A. White, 1987, The Pricing of Options on Assets with Stochastic Volatilities, Journal of Finance 42(2), 281-300.

Hwang, S., 2001a, Properties of Cross-sectional Volatility, Financial Econometric Research Centre working paper WP00-4, City University Business School.

Hwang, S. and Pedro Valls, 2001b, Properties of Volatility Persistence", Department of Banking and Finance Working Paper, City University Business School.

Hwang, S. and S. E. Satchell, 1998, Implied Volatility Forecasting: A Comparison of Different Procedures Including Fractionally Integrated Models with Applications to UK Equity Options, in J. Knight and S. Satchell eds., Forecasting Volatility in the Financial Markets, Butterworth-Heinemann, London.

Hwang, S. and S. E. Satchell, 2000, Market Risk and the Concept of Fundamental Volatility: Measuring Volatility across Asset and Derivative Markets and Testing for 
the Impact of Derivatives Markets on Financial Markets, Journal of Banking and Finance, forthcoming.

Knight, J., S. Hwang, and S. E. Satchell, 2001, Forecasting Nonlinear Functions of Returns Using LINEX Loss Functions, Annals of Economics and Finance, Vol. 2, $187-213$.

Jones, C. 2001, Extracting Factors from Heteroskedastic Asset Returns, forthcoming in Journal of Financial Economics.

MacDonald, J. A. and H. Shawky, 1995, On Estimation Stock Market Volatility: An Exploratory Approach, Journal of Financial Research 18(4), 449-463.

Apegis, N. T., 1998, Stock Market Volatility and Deviations from Macroeconomic Fundamentals: Evidence from GARCH and GARCH-X Models, Kredit und Kapital, Heft 3, 400-412.

Taylor, S. J., 1986, Modeling Financial Time Series, Chichester. 


\section{Table 1 Properties of Cross-sectional Volatility}

A. Properties of Cross-sectional and Time-series Equally Weighted Market Volatility

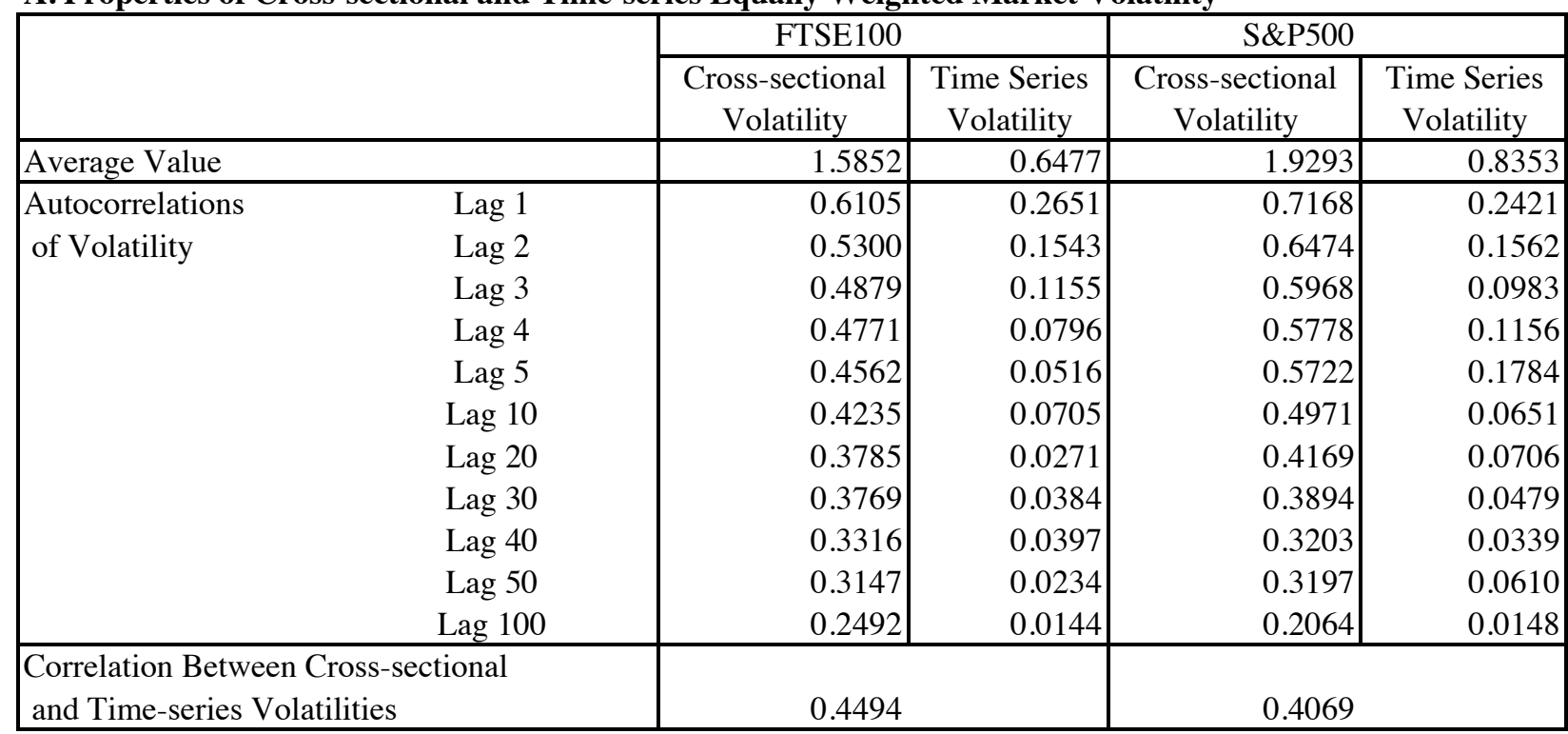

B. Properties of Cross-sectional and Time-series Value Weighted Market Volatility

\begin{tabular}{|c|c|c|c|c|c|}
\hline & & FTSE100 & & S\&P500 & \\
\hline & & $\begin{array}{c}\text { Cross-sectional } \\
\text { Volatility } \\
\end{array}$ & $\begin{array}{c}\text { Time Series } \\
\text { Volatility }\end{array}$ & $\begin{array}{c}\text { Cross-sectional } \\
\text { Volatility } \\
\end{array}$ & $\begin{array}{c}\text { Time Series } \\
\text { Volatility }\end{array}$ \\
\hline Average Value & & 1.3995 & 0.8328 & 1.6012 & 0.8876 \\
\hline Autocorrelations & Lag 1 & 0.6350 & 0.1682 & 0.6627 & 0.2358 \\
\hline of Volatility & Lag 2 & 0.5679 & 0.1886 & 0.6336 & 0.1449 \\
\hline & Lag 3 & 0.5269 & 0.1723 & 0.5890 & 0.0799 \\
\hline & Lag 4 & 0.5306 & 0.1441 & 0.5620 & 0.1114 \\
\hline & Lag 5 & 0.5265 & 0.1357 & 0.5642 & 0.1951 \\
\hline & Lag 10 & 0.5005 & 0.1469 & 0.4891 & 0.0821 \\
\hline & Lag 15 & 0.4637 & 0.1160 & 0.4301 & 0.0747 \\
\hline & Lag 20 & 0.4770 & 0.0762 & 0.4164 & 0.0699 \\
\hline & Lag 30 & 0.4087 & 0.1203 & 0.4121 & 0.0426 \\
\hline & Lag 40 & 0.3918 & 0.0923 & 0.3492 & 0.0481 \\
\hline & Lag 50 & 0.3671 & 0.0804 & 0.3617 & 0.0715 \\
\hline & Lag 100 & 0.3349 & 0.0584 & 0.3081 & 0.0313 \\
\hline $\begin{array}{l}\text { Correlation Betw } \\
\text { and Time-series }\end{array}$ & onal & 0.3990 & & 0.3856 & \\
\hline
\end{tabular}

Notes: The number of daily log-returns for the FTSE350 is 2532 from 11 December 1989 to 9 December 1999, and that for the S\&P500 is 2527 for the same sample period. Standard deviation rather than variance is used to obtain the properties in the above table. 
Table 2 Summary Table for Various Conditional Volatility Models

\begin{tabular}{|c|c|c|c|c|c|c|}
\hline \multicolumn{7}{|c|}{ A. FTSE350 } \\
\hline & & GARCH & GARCHX(EW) & GARCH-T(EW) & GARCHX(VW) & GARCH-T(VW) \\
\hline \multicolumn{2}{|l|}{ Total Number of Equities } & \multicolumn{5}{|c|}{333} \\
\hline \multicolumn{2}{|l|}{ Number of Converged Cases } & 323 & 311 & 286 & 316 & 312 \\
\hline \multirow[t]{2}{*}{ Maximum Likelihood Values } & $\begin{array}{c}\text { Number of Converged Cases } \\
\text { for all Five Models } \\
\end{array}$ & \multicolumn{5}{|c|}{278} \\
\hline & $\begin{array}{c}\text { Number of Cases which have } \\
\text { the Largest Maximum } \\
\text { Likelihood Values among the } \\
\text { Five Models }\end{array}$ & 46 & 96 & 10 & 109 & 17 \\
\hline Portmanteau Tests & $\mathrm{Q}(5)$ & $9.60 \%$ & $6.11 \%$ & $48.25 \%$ & $6.33 \%$ & $42.31 \%$ \\
\hline ( Percent of Significant Serial & $\mathrm{Q}(10)$ & $6.81 \%$ & $5.79 \%$ & $48.95 \%$ & $6.33 \%$ & $48.40 \%$ \\
\hline Correlation at $5 \%$ Level) & $\mathrm{Q}(20)$ & $7.74 \%$ & $8.36 \%$ & $56.64 \%$ & $8.54 \%$ & $54.81 \%$ \\
\hline \multicolumn{2}{|c|}{ Percent of Significant Skewness at 95\% Level } & $80.80 \%$ & $82.32 \%$ & $86.71 \%$ & $80.38 \%$ & $83.33 \%$ \\
\hline \multicolumn{2}{|c|}{ Percent of Significant Excess Kurtosis at 95\% Level } & $99.07 \%$ & $99.36 \%$ & $99.30 \%$ & $99.05 \%$ & $99.36 \%$ \\
\hline
\end{tabular}

\begin{tabular}{|c|c|c|c|c|c|c|}
\hline \multicolumn{7}{|l|}{ A. S\&P500 } \\
\hline & & GARCH & GARCHX(EW) & GARCH-T(EW) & GARCHX(VW) & GARCH-T(VW) \\
\hline \multicolumn{2}{|l|}{ Total Number of Equities } & \multicolumn{5}{|c|}{491} \\
\hline \multicolumn{2}{|l|}{ Number of Converged Cases } & 483 & 482 & 436 & 478 & 430 \\
\hline \multirow[t]{2}{*}{ Maximum Likelihood Values } & $\begin{array}{c}\text { Number of Converged Cases } \\
\text { for all Five Models }\end{array}$ & \multicolumn{5}{|c|}{421} \\
\hline & $\begin{array}{l}\text { Number of Cases which have } \\
\text { the Largest Maximum } \\
\text { Likelihood Values among the } \\
\text { Five Models }\end{array}$ & 33 & 237 & 12 & 122 & 17 \\
\hline Portmanteau Tests & $\mathrm{Q}(5)$ & $17.39 \%$ & $8.92 \%$ & $58.72 \%$ & $11.92 \%$ & $59.30 \%$ \\
\hline ( Percent of Significant Serial & $\mathrm{Q}(10)$ & $13.87 \%$ & $8.30 \%$ & $50.46 \%$ & $10.46 \%$ & $51.63 \%$ \\
\hline Correlation at 5\% Level) & $\mathrm{Q}(20)$ & $11.18 \%$ & $8.09 \%$ & $48.62 \%$ & $9.21 \%$ & $49.53 \%$ \\
\hline \multicolumn{2}{|c|}{ Percent of Significant Skewness at 95\% Level } & $66.25 \%$ & $65.98 \%$ & $67.20 \%$ & $66.95 \%$ & $64.88 \%$ \\
\hline \multicolumn{2}{|c|}{ Percent of Significant Excess Kurtosis at 95\% Level } & $100.00 \%$ & $99.79 \%$ & $100.00 \%$ & $100.00 \%$ & $100.00 \%$ \\
\hline
\end{tabular}




\section{Table 3 Detail Comparison of GARCH and GARCHX Models}

\begin{tabular}{|c|c|c|c|c|}
\hline \multicolumn{5}{|l|}{ A. FTSE350 } \\
\hline & & GARCH & GARCHX(EW) & GARCHX(VW) \\
\hline \multicolumn{2}{|c|}{$\begin{array}{l}\text { Percent of Significant Coefficients on Drift (GARCH) and } \\
\text { the Past CCS Volatility (GARCHX(EW) and GARCHX(VW))* }\end{array}$} & $81.42 \%$ & $87.14 \%$ & $87.66 \%$ \\
\hline \multicolumn{2}{|c|}{$\begin{array}{l}\text { Correlation Coefficient between Squared Betas and } \\
\text { Coefficients on the Past Cross-sectional Volatility }\end{array}$} & & 0.16 & -0.07 \\
\hline \multicolumn{2}{|c|}{$\begin{array}{l}\text { Percent of Cross-sectional Market Volatility } \\
\text { in the GARCHX Model }\end{array}$} & & $13.44 \%$ & $12.85 \%$ \\
\hline \multicolumn{2}{|c|}{ Number of Comparisons with GARCH Model } & - & 309 & 312 \\
\hline \multirow{3}{*}{$\begin{array}{c}\text { Aaveraged Increase in Maximum } \\
\text { Likelihood Values } \\
\text { Compared with those of GARCH } \\
\text { Model }\end{array}$} & $\begin{array}{c}\text { Number of Cases Where } \\
\text { GARCHX Has Larger Maximum } \\
\text { Likelihood Values Than GARCH }\end{array}$ & & 237 & 226 \\
\hline & $\begin{array}{c}\text { Averaged Increase in Maximum } \\
\text { Likelihood Values in Percent }\end{array}$ & & $0.55 \%$ & $0.49 \%$ \\
\hline & $\begin{array}{l}\text { Averaged Increase in Maximum } \\
\text { Likelihood Values }\end{array}$ & & 19.79 & 17.75 \\
\hline \multirow{3}{*}{$\begin{array}{l}\text { Averaged Portmanteau Test } \\
\text { Statistics for Squared Errors }\end{array}$} & $\mathrm{Q}(5)$ & 4.70 & 4.15 & 4.36 \\
\hline & $\mathrm{Q}(10)$ & 8.08 & 7.63 & 7.82 \\
\hline & $\mathrm{Q}(20)$ & 15.59 & 15.56 & 15.67 \\
\hline \multicolumn{2}{|c|}{ Averaged Skewness for Standardised Errors } & 0.30 & 0.25 & 0.27 \\
\hline \multicolumn{2}{|c|}{ Averaged Excess Kurtosis for Standardised Errors } & 12.04 & 11.04 & 11.12 \\
\hline
\end{tabular}




\begin{tabular}{|c|c|c|c|c|}
\hline & & GARCH & GARCHX(EW) & GARCHX(VW) \\
\hline \multicolumn{2}{|c|}{$\begin{array}{l}\text { Percent of Significant Coefficients on Drift (GARCH) and } \\
\text { the Past CCS Volatility (GARCHX(EW) and GARCHX(VW))* }\end{array}$} & $56.31 \%$ & $73.24 \%$ & $71.34 \%$ \\
\hline \multicolumn{2}{|c|}{ Correlation Coefficient between Squared Betas and } & & 0.40 & 0.32 \\
\hline \multicolumn{2}{|c|}{$\begin{array}{l}\text { Percent of Cross-sectional Market Volatility } \\
\text { in the GARCHX Model }\end{array}$} & & $15.87 \%$ & $12.22 \%$ \\
\hline \multicolumn{2}{|c|}{ Number of Comparisons with GARCH Model } & - & 480 & 478 \\
\hline \multirow{3}{*}{$\begin{array}{l}\text { Aaveraged Increase in Maximum } \\
\text { Likelihood Values } \\
\text { Compared with those of GARCH } \\
\text { Model }\end{array}$} & $\begin{array}{c}\text { Number of Cases Where } \\
\text { GARCHX Has Larger Maximum } \\
\text { Likelihood Values Than GARCH }\end{array}$ & - & 417 & 393 \\
\hline & $\begin{array}{l}\text { Averaged Increase in Maximum } \\
\text { Likelihood Values in Percent }\end{array}$ & & $0.30 \%$ & $0.23 \%$ \\
\hline & $\begin{array}{c}\text { Averaged Increase in Maximum } \\
\text { Likelihood Values } \\
\end{array}$ & & 14.48 & 11.06 \\
\hline \multirow{3}{*}{$\begin{array}{l}\text { Averaged Portmanteau Test } \\
\text { Statistics for Squared Errors }\end{array}$} & $\mathrm{Q}(5)$ & 6.67 & 4.67 & 5.52 \\
\hline & $\mathrm{Q}(10)$ & 10.05 & 8.35 & 9.12 \\
\hline & $\mathrm{Q}(20)$ & 17.77 & 17.23 & 17.75 \\
\hline \multicolumn{2}{|c|}{ Averaged Skewness for Standardised Errors } & -0.08 & -0.08 & -0.08 \\
\hline \multicolumn{2}{|c|}{ Averaged Excess Kurtosis for Standardised Errors } & 4.77 & 4.64 & 4.54 \\
\hline
\end{tabular}

Notes: The significance test marked with * is carried at $5 \%$ level. 
Table 4 Maximum Likelihood Estimates of GARCH(1,1) and GARCHX(1,1)

A. Abbey National

\begin{tabular}{|l|c|c|c|c|c|}
\hline Models & & $\alpha_{0}$ & $\alpha_{1}$ & $\alpha_{2}$ & $\begin{array}{c}\text { Maximum } \\
\text { Likelihood Values }\end{array}$ \\
\hline GARCH(1,1) & Estimates & 0.000003 & 0.0476 & 0.9471 & 6450.98 \\
& Standard Deviation & $(0.000003)$ & $(0.0270)$ & $(0.0339)$ & \\
\hline GARCHX(1,1) & Estimates & 0.002316 & 0.0769 & 0.8139 & 6469.83 \\
& Standard Deviation & $(0.001464)$ & $(0.0236)$ & $(0.0860)$ & \\
\hline
\end{tabular}

\section{B. Unilever}

\begin{tabular}{|l|c|c|c|c|c|}
\hline Models & & $\alpha_{0}$ & $\alpha_{1}$ & $\alpha_{2}$ & $\begin{array}{c}\text { Maximum } \\
\text { Likelihood Values }\end{array}$ \\
\hline GARCH(1,1) & Estimates & 0.000001 & 0.0471 & 0.9525 & 7196.72 \\
& Standard Deviation & $(0.000001)$ & $(0.0156)$ & $(0.0175)$ & \\
\hline GARCHX(1,1) & Estimates & 0.000110 & 0.0495 & 0.9438 & 7200.76 \\
& Standard Deviation & $(0.000081)$ & $(0.0149)$ & $(0.0193)$ & \\
\hline
\end{tabular}

\section{British Airways}

\begin{tabular}{|l|c|c|c|c|c|}
\hline Models & & $\alpha_{0}$ & $\alpha_{1}$ & $\alpha_{2}$ & $\begin{array}{c}\text { Maximum } \\
\text { Likelihood Values }\end{array}$ \\
\hline GARCH(1,1) & Estimates & 0.000005 & 0.0861 & 0.9079 & 6353.35 \\
& Standard Deviation & $(0.000008)$ & $(0.0805)$ & $(0.0885)$ & \\
\hline GARCHX(1,1) & Estimates & 0.001264 & 0.1113 & 0.8426 & 6364.04 \\
& Standard Deviation & $(0.001187)$ & $(0.0753)$ & $(0.1114)$ & \\
\hline
\end{tabular}

\section{FTSE100 Index}

\begin{tabular}{|l|c|c|c|c|c|}
\hline Models & & $\alpha_{0}$ & $\alpha_{1}$ & $\alpha_{2}$ & $\begin{array}{c}\text { Maximum } \\
\text { Likelihood Values }\end{array}$ \\
\hline GARCH(1,1) & Estimates & 0.000001 & 0.0724 & 0.9177 & 8184.52 \\
& Standard Deviation & $(0.000001)$ & $(0.0243)$ & $(0.0314)$ & \\
\hline GARCHX(1,1) & Estimates & 0.000182 & 0.0716 & 0.8963 & 8192.56 \\
& Standard Deviation & $(0.000065)$ & $(0.0157)$ & $(0.0225)$ & \\
\hline
\end{tabular}

Notes: Returns from 21 January 1992 to 27 November 2001 for a total of 2496 observations are used. 
Table 5 Forecasting Performance of GARCH(1,1)-RV and GARCHX(1,1)-RV for RV

A. Abbey National

\begin{tabular}{|c|c|c|c|c|}
\hline \multirow{2}{*}{$\begin{array}{c}\text { Forecasting } \\
\text { Horizons }\end{array}$} & \multicolumn{3}{|c|}{ GARCH(1,1) } & \multicolumn{2}{c|}{ GARCHX $(1,1)$} \\
\cline { 2 - 5 } & MAFE & MSFE & MAFE & MSFE \\
\hline 1 & 0.1230 & 0.0642 & 0.1225 & 0.0636 \\
3 & 0.1243 & 0.0647 & 0.1239 & 0.0641 \\
4 & 0.1264 & 0.0659 & 0.1260 & 0.0654 \\
5 & 0.1267 & 0.0659 & 0.1262 & 0.0653 \\
6 & 0.1411 & 0.1143 & 0.1406 & 0.1141 \\
7 & 0.1458 & 0.1203 & 0.1459 & 0.1206 \\
8 & 0.1461 & 0.1203 & 0.1462 & 0.1205 \\
9 & 0.1465 & 0.1202 & 0.1462 & 0.1199 \\
10 & 0.1460 & 0.1198 & 0.1471 & 0.1201 \\
15 & 0.1451 & 0.1194 & 0.1461 & 0.1199 \\
20 & 0.1451 & 0.1168 & 0.1456 & 0.1178 \\
25 & 0.1455 & 0.1168 & 0.1486 & 0.1189 \\
30 & 0.1488 & 0.1182 & 0.1523 & 0.1209 \\
40 & 0.1467 & 0.1163 & 0.1495 & 0.1184 \\
50 & 0.1427 & 0.1151 & 0.1466 & 0.1156 \\
60 & 0.1440 & 0.1142 & 0.1457 & 0.1149 \\
\hline
\end{tabular}

\section{B. Unilever}

\begin{tabular}{|c|c|c|c|c|}
\hline \multirow{2}{*}{$\begin{array}{c}\text { Forecasting } \\
\text { Horizons }\end{array}$} & \multicolumn{3}{|c|}{ GARCH(1,1) } & \\
\cline { 2 - 5 } & MAFE & MSFE & MAFE & MSFE \\
\hline 1 & 0.0656 & 0.0112 & 0.0655 & 0.0112 \\
2 & 0.0658 & 0.0112 & 0.0656 & 0.0112 \\
3 & 0.0658 & 0.0111 & 0.0657 & 0.0111 \\
4 & 0.0659 & 0.0111 & 0.0658 & 0.0111 \\
5 & 0.0674 & 0.0117 & 0.0673 & 0.0117 \\
6 & 0.0667 & 0.0116 & 0.0665 & 0.0115 \\
7 & 0.0682 & 0.0120 & 0.0680 & 0.0120 \\
8 & 0.0694 & 0.0124 & 0.0693 & 0.0123 \\
9 & 0.0706 & 0.0128 & 0.0704 & 0.0128 \\
10 & 0.0712 & 0.0129 & 0.0710 & 0.0128 \\
15 & 0.0763 & 0.0168 & 0.0762 & 0.0167 \\
20 & 0.0807 & 0.0190 & 0.0806 & 0.0189 \\
25 & 0.0809 & 0.0192 & 0.0807 & 0.0190 \\
30 & 0.0829 & 0.0196 & 0.0825 & 0.0194 \\
40 & 0.0806 & 0.0187 & 0.0803 & 0.0185 \\
50 & 0.0815 & 0.0184 & 0.0806 & 0.0181 \\
60 & 0.0795 & 0.0161 & 0.0788 & 0.0157 \\
\hline
\end{tabular}


C. British Airways

\begin{tabular}{|c|c|c|c|c|}
\hline \multirow{2}{*}{$\begin{array}{c}\text { Forecasting } \\
\text { Horizons }\end{array}$} & \multicolumn{3}{|c|}{ GARCH(1,1) } & \\
\cline { 2 - 4 } & MAFE & MSFE & MAFE & MSFE \\
\hline 1 & 0.1707 & 0.0857 & 0.1659 & 0.0851 \\
3 & 0.1763 & 0.0932 & 0.1710 & 0.0926 \\
4 & 0.1767 & 0.0936 & 0.1710 & 0.0930 \\
5 & 0.1776 & 0.0944 & 0.1714 & 0.0938 \\
6 & 0.2356 & 0.9266 & 0.2296 & 0.9263 \\
7 & 0.2353 & 0.9264 & 0.2289 & 0.9266 \\
8 & 0.2394 & 0.9297 & 0.2327 & 0.9293 \\
9 & 0.2700 & 1.1549 & 0.2635 & 1.1545 \\
10 & 0.2735 & 1.1584 & 0.2666 & 1.1586 \\
15 & 0.2730 & 1.1590 & 0.2660 & 1.1590 \\
20 & 0.3033 & 1.2708 & 0.2950 & 1.2714 \\
25 & 0.3136 & 1.2776 & 0.3055 & 1.2785 \\
30 & 0.3221 & 1.2819 & 0.3152 & 1.2848 \\
40 & 0.3098 & 1.2580 & 0.3012 & 1.2590 \\
50 & 0.3311 & 1.3388 & 0.3219 & 1.3416 \\
60 & 0.3538 & 1.3616 & 0.3440 & 1.3664 \\
& 0.3906 & 1.5355 & 0.3833 & 1.5479 \\
\hline
\end{tabular}

D. FTSE100 Index

\begin{tabular}{|c|c|c|c|c|}
\hline \multirow{2}{*}{$\begin{array}{c}\text { Forecasting } \\
\text { Horizons }\end{array}$} & \multicolumn{3}{|c|}{ GARCH(1,1) } & \\
\cline { 2 - 5 } & MAFE & MSFE & MAFE & MSFE \\
\hline 1 & 0.0343 & 0.0028 & 0.0339 & 0.0028 \\
2 & 0.0350 & 0.0029 & 0.0345 & 0.0029 \\
3 & 0.0357 & 0.0030 & 0.0351 & 0.0030 \\
4 & 0.0358 & 0.0030 & 0.0352 & 0.0030 \\
5 & 0.0396 & 0.0061 & 0.0390 & 0.0061 \\
6 & 0.0405 & 0.0063 & 0.0399 & 0.0063 \\
7 & 0.0405 & 0.0063 & 0.0398 & 0.0063 \\
8 & 0.0421 & 0.0069 & 0.0413 & 0.0068 \\
9 & 0.0430 & 0.0071 & 0.0422 & 0.0070 \\
10 & 0.0430 & 0.0071 & 0.0421 & 0.0081 \\
15 & 0.0461 & 0.0082 & 0.0453 & 0.0083 \\
20 & 0.0472 & 0.0083 & 0.0466 & 0.0084 \\
25 & 0.0472 & 0.0084 & 0.0467 & 0.0085 \\
30 & 0.0479 & 0.0085 & 0.0474 & 0.0086 \\
40 & 0.0489 & 0.0087 & 0.0483 & 0.0085 \\
50 & 0.0476 & 0.0085 & 0.0471 & 0.0085 \\
60 & 0.0463 & 0.0084 & 0.0464 & \\
\hline
\end{tabular}

Notes: Return and implied volatilities from 21 January 1992 to 27 November 2001 for a total of 2496 observations are used. Recent 2197 observations are used for estimating models and forecasting volatility over 60 horizons. MAFE and MSFE represent mean absolute forecast error and mean squared forecast error, respectively. The results are based on 240 out-of-sample forecasts. 


\section{List of other working papers:}

\section{1}

1. Soosung Hwang and Steve Satchell, GARCH Model with Cross-sectional Volatility; GARCHX Models, WP01-16

2. Soosung Hwang and Steve Satchell, Tracking Error: Ex-Ante versus Ex-Post Measures, WP01-15

3. Soosung Hwang and Steve Satchell, The Asset Allocation Decision in a Loss Aversion World, WP01-14

4. Soosung Hwang and Mark Salmon, An Analysis of Performance Measures Using Copulae, WP01-13

5. Soosung Hwang and Mark Salmon, A New Measure of Herding and Empirical Evidence, WP01-12

6. Richard Lewin and Steve Satchell, The Derivation of New Model of Equity Duration, WP0111

7. Massimiliano Marcellino and Mark Salmon, Robust Decision Theory and the Lucas Critique, WP01-10

8. Jerry Coakley, Ana-Maria Fuertes and Maria-Teresa Perez, Numerical Issues in Threshold Autoregressive Modelling of Time Series, WP01-09

9. Jerry Coakley, Ana-Maria Fuertes and Ron Smith, Small Sample Properties of Panel Timeseries Estimators with I(1) Errors, WP01-08

10. Jerry Coakley and Ana-Maria Fuertes, The Felsdtein-Horioka Puzzle is Not as Bad as You Think, WP01-07

11. Jerry Coakley and Ana-Maria Fuertes, Rethinking the Forward Premium Puzzle in a Nonlinear Framework, WP01-06

12. George Christodoulakis, Co-Volatility and Correlation Clustering: A Multivariate Correlated ARCH Framework, WP01-05

13. Frank Critchley, Paul Marriott and Mark Salmon, On Preferred Point Geometry in Statistics, WP01-04

14. Eric Bouyé and Nicolas Gaussel and Mark Salmon, Investigating Dynamic Dependence Using Copulae, WP01-03

15. Eric Bouyé, Multivariate Extremes at Work for Portfolio Risk Measurement, WP01-02

16. Erick Bouyé, Vado Durrleman, Ashkan Nikeghbali, Gael Riboulet and Thierry Roncalli, Copulas: an Open Field for Risk Management, WP01-01

\section{0}

1. Soosung Hwang and Steve Satchell, Valuing Information Using Utility Functions, WP00-06

2. Soosung Hwang, Properties of Cross-sectional Volatility, WP00-05

3. Soosung Hwang and Steve Satchell, Calculating the Miss-specification in Beta from Using a Proxy for the Market Portfolio, WP00-04

4. Laun Middleton and Stephen Satchell, Deriving the APT when the Number of Factors is Unknown, WP00-03

5. George A. Christodoulakis and Steve Satchell, Evolving Systems of Financial Returns: AutoRegressive Conditional Beta, WP00-02

6. Christian S. Pedersen and Stephen Satchell, Evaluating the Performance of Nearest Neighbour Algorithms when Forecasting US Industry Returns, WP00-01

1999

1. Yin-Wong Cheung, Menzie Chinn and Ian Marsh, How do UK-Based Foreign Exchange Dealers Think Their Market Operates?, WP99-21 
2. Soosung Hwang, John Knight and Stephen Satchell, Forecasting Volatility using LINEX Loss Functions, WP99-20

3. Soosung Hwang and Steve Satchell, Improved Testing for the Efficiency of Asset Pricing Theories in Linear Factor Models, WP99-19

4. Soosung Hwang and Stephen Satchell, The Disappearance of Style in the US Equity Market, WP99-18

5. Soosung Hwang and Stephen Satchell, Modelling Emerging Market Risk Premia Using Higher Moments, WP99-17

6. Soosung Hwang and Stephen Satchell, Market Risk and the Concept of Fundamental Volatility: Measuring Volatility Across Asset and Derivative Markets and Testing for the Impact of Derivatives Markets on Financial Markets, WP99-16

7. Soosung Hwang, The Effects of Systematic Sampling and Temporal Aggregation on Discrete Time Long Memory Processes and their Finite Sample Properties, WP99-15

8. Ronald MacDonald and Ian Marsh, Currency Spillovers and Tri-Polarity: a Simultaneous Model of the US Dollar, German Mark and Japanese Yen, WP99-14

9. Robert Hillman, Forecasting Inflation with a Non-linear Output Gap Model, WP99-13

10. Robert Hillman and Mark Salmon , From Market Micro-structure to Macro Fundamentals: is there Predictability in the Dollar-Deutsche Mark Exchange Rate?, WP99-12

11. Renzo Avesani, Giampiero Gallo and Mark Salmon, On the Evolution of Credibility and Flexible Exchange Rate Target Zones, WP99-11

12. Paul Marriott and Mark Salmon, An Introduction to Differential Geometry in Econometrics, WP99-10

13. Mark Dixon, Anthony Ledford and Paul Marriott, Finite Sample Inference for Extreme Value Distributions, WP99-09

14. Ian Marsh and David Power, A Panel-Based Investigation into the Relationship Between Stock Prices and Dividends, WP99-08

15. Ian Marsh, An Analysis of the Performance of European Foreign Exchange Forecasters, WP99-07

16. Frank Critchley, Paul Marriott and Mark Salmon, An Elementary Account of Amari's Expected Geometry, WP99-06

17. Demos Tambakis and Anne-Sophie Van Royen, Bootstrap Predictability of Daily Exchange Rates in ARMA Models, WP99-05

18. Christopher Neely and Paul Weller, Technical Analysis and Central Bank Intervention, WP9904

19. Christopher Neely and Paul Weller, Predictability in International Asset Returns: A Reexamination, WP99-03

20. Christopher Neely and Paul Weller, Intraday Technical Trading in the Foreign Exchange Market, WP99-02

21. Anthony Hall, Soosung Hwang and Stephen Satchell, Using Bayesian Variable Selection Methods to Choose Style Factors in Global Stock Return Models, WP99-01

\section{8}

1. Soosung Hwang and Stephen Satchell, Implied Volatility Forecasting: A Compaison of Different Procedures Including Fractionally Integrated Models with Applications to UK Equity Options, WP98-05

2. Roy Batchelor and David Peel, Rationality Testing under Asymmetric Loss, WP98-04

3. Roy Batchelor, Forecasting T-Bill Yields: Accuracy versus Profitability, WP98-03

4. Adam Kurpiel and Thierry Roncalli, Option Hedging with Stochastic Volatility, WP98-02

5. Adam Kurpiel and Thierry Roncalli, Hopscotch Methods for Two State Financial Models, WP98-01 